\title{
Continuous cleaning process of molten copper slags in a channel reactor under the external electric field
}

\author{
Mingjun Zhang ${ }^{1}$, Li $\mathrm{Fu}^{1,2}$, Huaiwei Zhang ${ }^{1 *}$ \\ ${ }^{1}$ College of Materials and Environmental Engineering, Hangzhou Dianzi University, Hangzhou 310018, PR China \\ ${ }^{2}$ Key Laboratory of Bee Products for Quality and Safety Control, Ministry of Agriculture, Institute of Apicultural Research, \\ Chinese Academy of Agricultural Sciences Beijing 100093, PR China
}

\begin{abstract}
Continuous cleaning process of the molten copper slags in a channel reactor under a vertical electric field is proposed. The copper-matte settling velocity under the vertical electric field is much faster than that only under the gravity in the molten slags, and the electric field can also accelerate the magnetite reduction. $\mathrm{Cu}$ content in the slag can fall below $0.35 \mathrm{wt}$ \% during the continuous cleaning process, which exceeds much more existing slag treatment process. In addition, the behaviours of some other heavy metal elements in the molten slags during the continuous process are also discussed.
\end{abstract}

\section{Introduction}

The slag cleaning process is the essential component in the copper production industry [1-4]. The traditional slag cleaning process including slag reduction and quiet sedimentation has higher energy consumption and lower efficiency [5-7]. With the increasing depletion of copper resources, the more efficient treatment process of the copper slags should be developed. In the copper smelting slags, physically entrapped and chemically dissolved are the main reasons for the copper losses.

Due to the molten slags ionic structures, it can improve the cleaning process by the application of the electro-capillary effect in accelerating the copper-matte drops settling [8-13]. The behaviors of matte droplets in the molten slags under a vertical electric field are studied by Choo et al, and the slags and matte composition can significantly affect the migration direction of the droplets [12-13]. Warczok et al [14] investigated that the copper droplets can migrate to the cathode in the molten $\mathrm{CaO}-\mathrm{SiO}_{2}-\mathrm{Al}_{2} \mathrm{O}_{3}$ slag in the external electric filed. The copper recovery rate is significantly improved [15]. The same results were obtained in our previous studies [16].

On the other hand, the electrolysis reactions can be generated in the surface of the electrodes and molten slags. Metallic copper will be generated around the cathode during the electrolysis process of molten $\mathrm{Cu}_{2} \mathrm{O}$ containing slag [8]. Iron-rich phases are formed around the cathode for the $\mathrm{FeO}_{\mathrm{x}}$-containing $\mathrm{CaO}-\mathrm{Al}_{2} \mathrm{O}_{3}-\mathrm{SiO}_{2}$ molten slags under the constant current field [9]. Fan et al [17-18] develop a method to selective precipitation of magnetite in the copper molten slag for downstream iron separation by using high-voltage electrical pulses.

Through above discussion, external electric field has the wide application prospects in the copper slag cleaning process. In this paper, continuous copper slag cleaning process in vertical DC electric field (CVDCF) is developed. A channel type of furnace with continuous slag feeding system is applied during the process.

\section{Experimental apparatus and procedure}

The apparatus for molten copper slag cleaning in flow condition is shown in Fig.1. An alumina reaction crucible is placed in channel reactor by using $\mathrm{MoSi}_{2}$ bar as the heating device. Then, metallic copper power (as cathode), copper slag and graphite powder (as anode) are added to the crucible in order. Two graphite rods are immersed into the electrodes, and they are connected to high-power linear DC voltage-stabilized power sources equipment. The temperature is determined through the $\mathrm{Pt}-\mathrm{Pt} / \mathrm{Rh}$ thermocouples. All the experiments are performed under the pure Ar gas circumstance.

The original materials used in the experiment are the copper-converting slags. The compositions are the $\mathrm{FeO}-$ $\mathrm{SiO}_{2}-\mathrm{Fe}_{3} \mathrm{O}_{4}$ based slags with 4.36 wt.\% copper, as shown in Table 1. We expect to control the molten slag flowing conditions by controlling the feeding rate. The feeding and sampling regimes of the copper slags were shown in Fig.2. The samples after the experiments are analyzed by XRF (X-ray fluorescence, XRF-1800, Shimadzu), XRD (X-ray diffraction, D/max 2000 diffractometer, Rigaku), ICP-AES (inductive coupled plasma emission spectrometer, PE 8300DV, Perkin-Elmer) and direct weighting.

\section{Results and discussion}

The copper-matte droplets in the molten slags can be aggregated at the bottom of the furnace hearth under the effects of gravitational and electrostatic forces. The

\footnotetext{
* Corresponding author: zhw5984@hdu.edu.cn
} 
movements of the matte droplets can be seen as the synthesis of vertical and horizontal, as shown in Fig.3. In the horizontal direction, the droplets motion velocity is equal to the molten slag flow velocity approximately as the following equation:

$v_{x}=\frac{Q}{\rho_{s} \cdot \omega \cdot h}$

$v_{x}$-Droplets motion velocity in the horizontal direction $/ \mathrm{m} \cdot \mathrm{s}^{-1}$

$Q-$ Feeding rate $/ \mathrm{kg} \cdot \mathrm{s}^{-1}$

$\rho_{s}-$ Molten slag density $/ \mathrm{kg} \cdot \mathrm{m}^{-3}$

$w$-Device width / $m$

$h$-Molten slag thickness $/ m$

The droplets residence time in the horizontal direction can be obtained as follow:

$t_{x}=\frac{l}{v_{x}}$

\section{l-Device length $/ m$}

So,

$t_{x}=\frac{\rho_{s} \cdot \omega \cdot h \cdot l}{Q}=\frac{\rho_{s} \cdot V}{Q}$

$V$-Device volume $/ \mathrm{m}^{3}$

The droplets residence time in the vertical direction can be obtained as follow:

$t_{y}=\frac{h}{v_{y}}$

$v_{y}$-Droplets motion velocity in the vertical direction $/ \mathrm{m} \cdot \mathrm{s}^{-1}$

The copper droplets residence time in the cleaning furnace is depended on the residence time in the horizontal direction, and the increase of the $t_{x}$ is benefit for the cleaning process. From equation 3, increasing furnace hearth size and decreasing the molten slag flow rate and prolong the droplets horizontal residence time. Meanwhile, the decreasing of $t_{y}$ can accelerate the copper droplets settlement, and the efficient methods are to reduce the slag layer thickness and promote the droplets settling rate. In our experiments, it is hard to change the furnace size $(l)$ and the molten slag thickness (h).

Table 1 Chemical composition of slags/ wt.\%

\begin{tabular}{|c|c|}
\hline Components & Contents / wt.\% \\
\hline $\mathrm{FeO}$ & 47.38 \\
\hline $\mathrm{Fe}_{3} \mathrm{O}_{4}$ & 7.37 \\
\hline $\mathrm{SiO}_{2}$ & 33.54 \\
\hline $\mathrm{CaO}$ & 3.00 \\
\hline $\mathrm{Cu}$ & 4.36 \\
\hline $\mathrm{ZnO}$ & 1.90 \\
\hline $\mathrm{PbS}$ & 1.71 \\
\hline Others & 0.74 \\
\hline
\end{tabular}

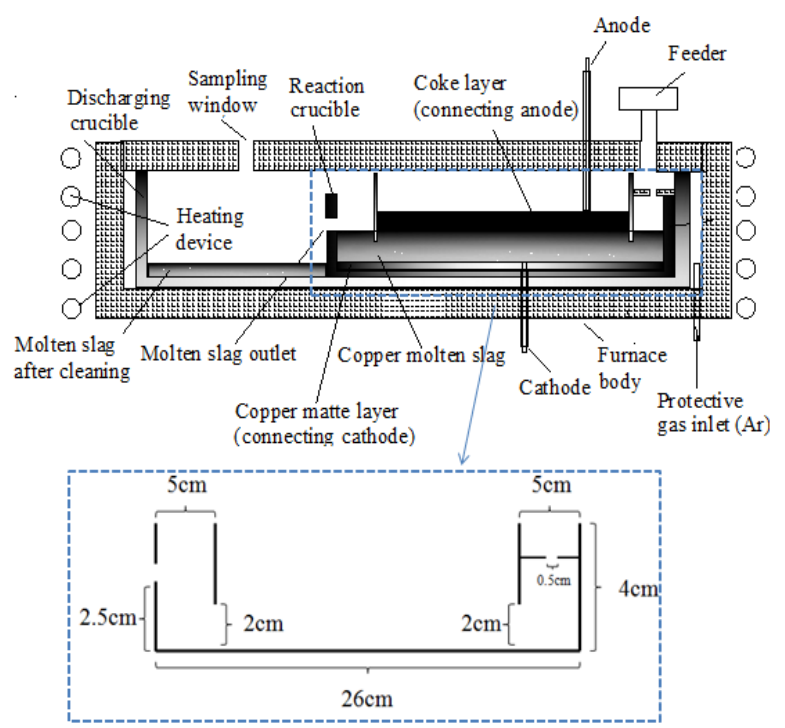

Fig.1 Experimental apparatus and the internal size during the molten copper slags cleaning process under the vertical electric field

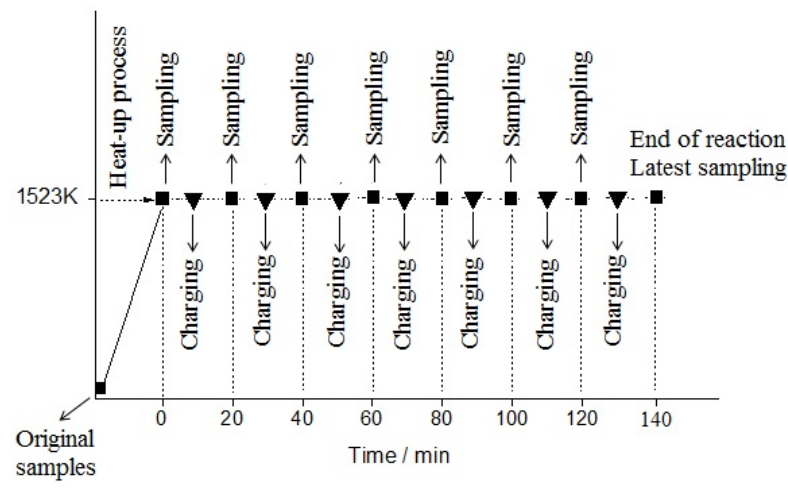

Fig.2 Feeding-sampling regimes of the molten slags

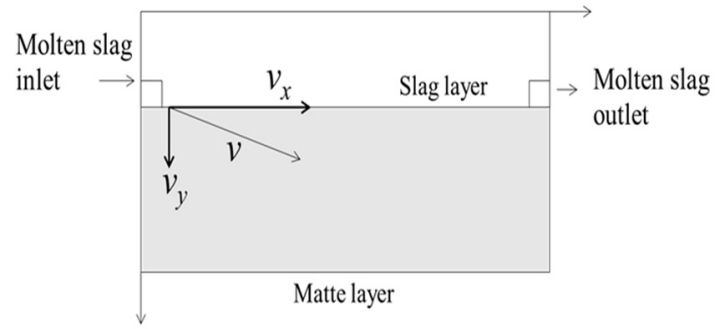

Fig.3 Description of the matte droplets settling track

We need to appropriately control the feeding rate (Q) to prolong the copper droplets residence time in the furnace. On the other hand, the droplets settling rate can be accelerated through the external electric field. The copper contents of the slag as the function of time during the continuous cleaning process in the vertical electric field are shown in Fig.4. The copper contents in the molten slags remained unchanged basically when the electric intensity is increased to $1.5 \mathrm{~V} / \mathrm{cm}$ after $100 \mathrm{~min}$ (Fig.4a) and when the feeding rate is less than $3.0 \mathrm{~g} / \mathrm{min}$ after $120 \min (4 b)$. 

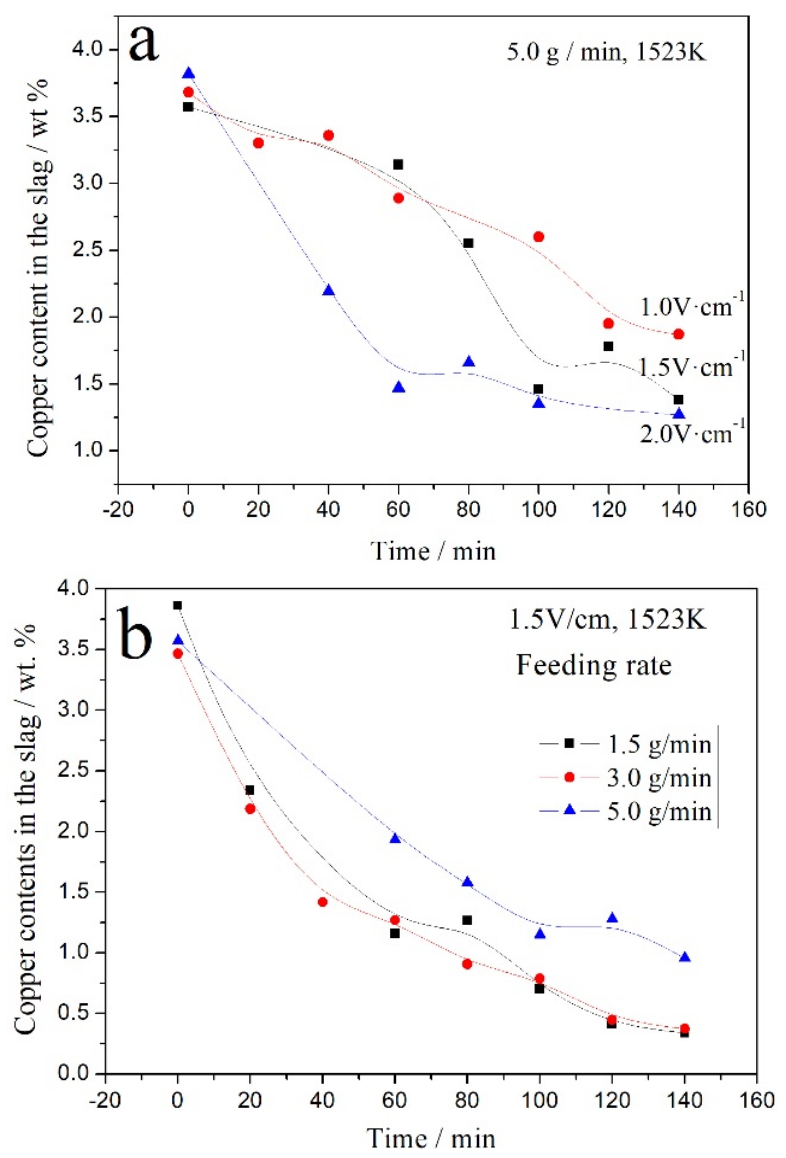

Fig.4 Copper contents as a function of time with various electric field intensities (a) and slag feeding rates (b) during the CVDCF process
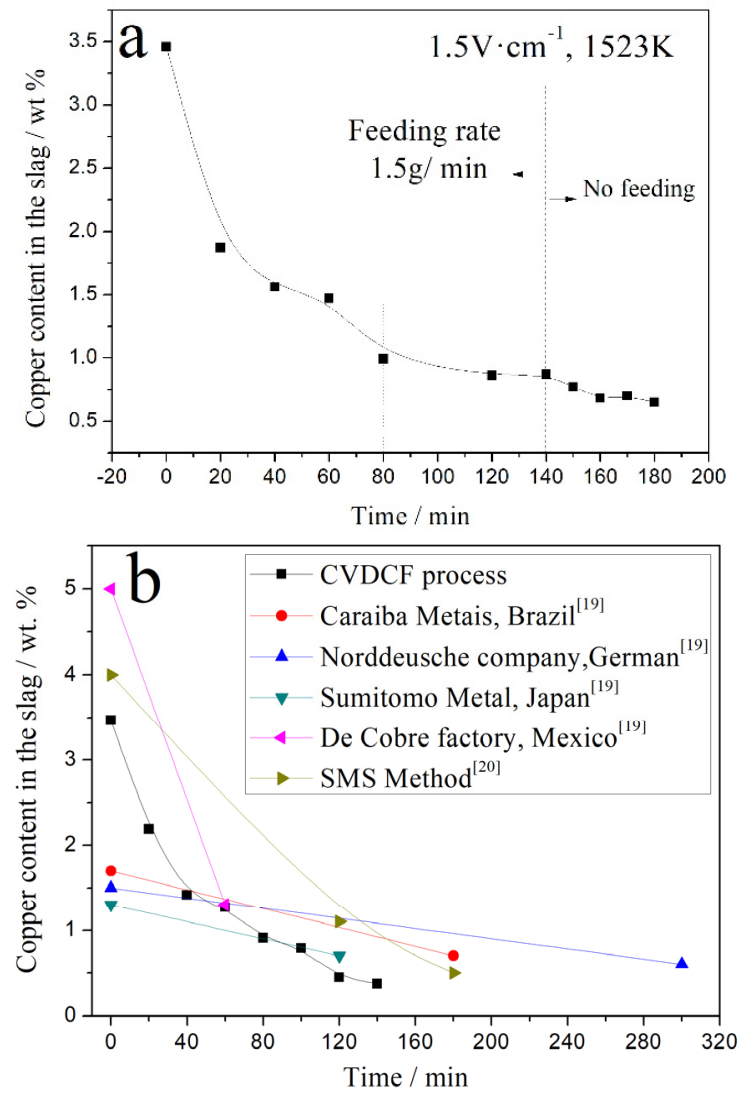

Fig.5 Optimization experiment of CVDCF process (a) and the comparisons with the main cleaning processes $(b)$
The results of the optimization experiment are shown in Fig.5a. The copper contents in the slag will fall below $0.35 \%$, and keep the relatively stable value when the feeding rate is less than $3.0 \mathrm{~g} / \mathrm{min}$ at the electric field intensity of $1.5 \mathrm{~V} / \mathrm{cm}$ in the tests. Comparing to the mainstream copper slag cleaning processes (Fig.5b), the CVDCF process has great advantages in both cleaning duration and efficiency.

Variety regulations of some other elements in the copper slag during the continuous CVDCF process are also investigated, as shown as Fig.6a. From the picture, the contents of $\mathrm{Zn}$ and $\mathrm{Pb}$ are decreased in the cleaning process. This illustrates that the application of CVDCF process is propitious to the removal of some heavy metal elements from the copper slag, and produces the active effects on the subsequent processing. Otherwise, the $\mathrm{Al}$ contents are increased at the same time. The electrolysis can also celebrate the reaction crucible corrosion process. How to avoid or reduce the reactor corrosion while during the CVDCF process is a problem in the further experiments.

The phases transitions during the CVDCF process are displayed in Fig.6b. The peaks of $\mathrm{Cu}$ and $\mathrm{PbS}$ are gradually weakened with the increase of the duration. There are obvious effects to the copper and lead recovery. The diffraction intensity of magnetite is also decreasing during the process, and the fayalite intensity is strengthened at the same time. The possible reason for the phenomenon is that the strong electric field can course the decomposition of $\mathrm{Fe}_{3} \mathrm{O}_{4}$ into $\mathrm{FeO}$ and $\mathrm{O}_{2}$. The results are generally consistent with those obtained through the CVDCF process.
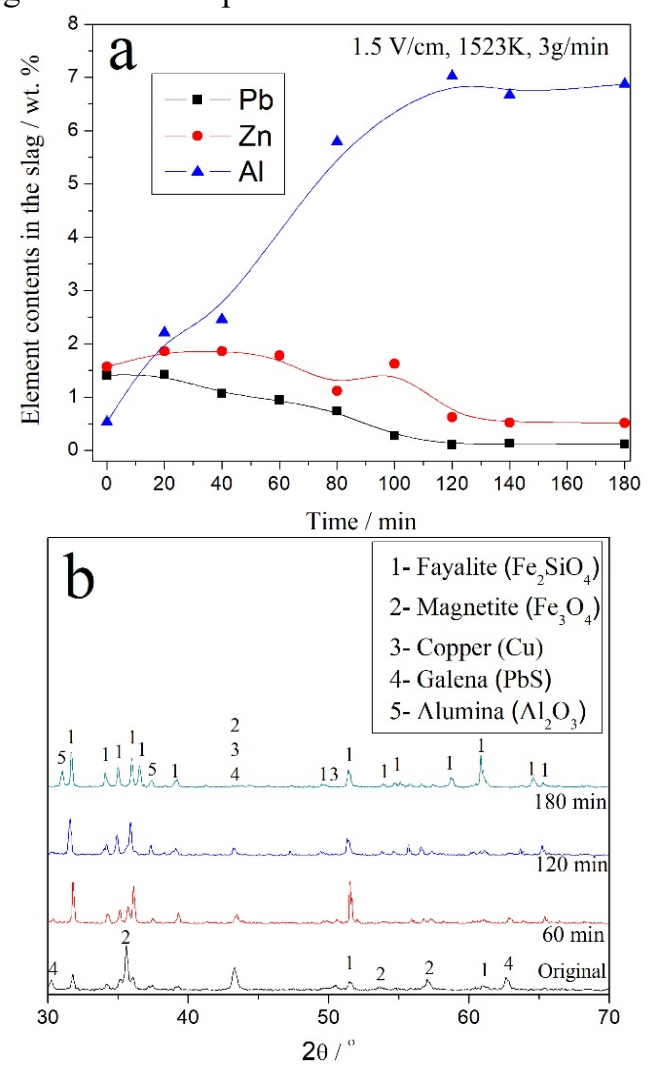

Fig.6 Elements contents (a) and copper slag phases (a) during CVDCF process 


\section{Conclusions}

Continuous cleaning process of the molten copper slags under the vertical electric field (CVDCF process) is studied in the paper. Some conclusions are as following according to the above discussion:

(1) The cleaning process of the molten copper slags can be improved efficiently by the external electric field. The copper-matte settling rates in the molten slags under the electric field are much higher than that only under the gravity.

(2) The copper contents in the slags can fall below $0.35 \%$ in the CVDCF process. Comparing to the main copper slag cleaning processes, the process has great advantages in both cleaning duration and efficiency.

(3) The application of external electric field in the slag cleaning process is propitious to the removal of some heavy metal elements from the slag, and produces the active effects on the subsequent processing.

\section{Acknowledgements}

The study is funded by the Agricultural Science and Technology Innovation Program (CAAS-ASTIP-2017IAR).

\section{References}

1 . B.Gorai, R.K.Jana, Resour.Conserv. Recy. 39 (2003) 299-313.

2. A.Agrawal, K.K.Sahu, Resour.Conserv. Recy. 54 (2010) 401-416.

3 . Z.L.Zuo, Q.B.Yu, S.H.Liu, H.Q.Xie, W.J.Duan, J.X.Liu, Q.Qin, S.G.Yang, J.Therm.Anal.Calorim. 131 (2018) 1691-1698.

4 . K.Avarmaa, S.Yliaho, P.Taskinen,Waste Manage. 71 (2018) 400-410.

5 . A. Warczok, G.Riveros, P.Echeverría, C.M.Díaz, H.Schwarze, G.Sánchez, Can.Metall.Quart. 41 (2002) 465-473.

6 . S.Demetrio, A.Jorge, M.A.Duran, E.Mast, U.Rojas, J.Sanhueza, JOM 52 (2000) 20-25.

7 . P.Sarfo, G.Wyss, G.J.Ma A.Das, C.Young, Miner.Eng. 107 (2017) 8-19.

8. A.Warczok, G.Riveros, Can.Metall.Quart. 2005, 44(4), 563-570.

9 . J.H.Liu, G.H.Zhang, K.C.Chou, J.Electrochem.Soc. 162 (2015) E314-E318.

10 . Y.M.Gao, C.Hong, C.H.Yang, J.Electrochem.Soc. 162 (2015) E362-E369.

11 . Y.M.Gao, C.Duan, Y.B.Yang, D.Ruan, C.H.Yang, C.Hong, ISIJ Int. 55 (2015) 2273-2282.

12 . R.T.C.Choo, J.M.Toguri, Can.Metall.Quart. 31 (1992) 113-126.

13 . S.Itoh, R.T.C.Choo, J.M.Toguri, Can.Metall.Quart. 34 (1992) 319-330.
14 . A.Warczok, T.A.Utigard, Metall.Mater.Trans.B 26 (1995)1165-1173.

15 . A.Warczok, G.Riveros, Miner.Eng. 20 (2007) 3443.

16 . H.W.Zhang, X.Y.Shi, B.Zhang, X.Hong, ISIJ Int. 53 (2013) 1704-1708.

17. Y.Fan, E.Shibata, A.Iizuka, T.Nakamura, Metall.Mater.Trans.B 46 (2015) 2158-2164.

18. Y.Fan, E.Shibata, A.Iizuka, T.Nakamura, Metall.Mater.Trans.B 47 (2016) 2754-2760.

19 . M.E.Schlesinger, M.J.King, K.C. Sole, and W.G.Davenport, 2011. Extractive metallurgy of copper, fifth Ed. Elsevier, Amsterdam.

20 . R.Degel, H.Oterdoom, J.Kunze, A.Warczok, G.Riveros, Third International Platinum Conference 'Platinum in Transformation', The Southern African Institute of Mining and Metallurgy, 2008. 197-202. 